\title{
TRACHEAL TUBE CUFF VOLUME CHANGES DURING EXTRACORPOREAL CIRCULATION
}

\author{
Shigemasa lkeda and John F. Schweiss
}

ABSTRACT

\begin{abstract}
Changes in the volume of tracheal tube cuffs were examined during extracorporeal circulation to determine the influence of the composition of the inspired gases and of the gas within the cuff. The study was carried out on 90 patients who underwent coronary artery bypass grafting.

When the cuff contains nitrous oxide at the start of extracorporeal circulation, the cuff volume decreases during bypass regardless of the composition of the inspired gases. When the cuff is filled with air or 100 per cent oxygen at the start of extracorporeal circulation and the inspired gas mixture consists of nitrous oxide and oxygen the cuff volume increases. When the cuff is deflated and then refilled with either room air or oxygen at the beginning of the extracorporeal circulation and the lungs are inflated with oxygen, the cuff volume change is minimal during bypass. This combination of gas prevents any undesirable change in the cuff volume. It appears desirable to monitor the tracheal tube cuff volume or pressure and to maintain a constant pressure and volume during bypass to prevent deflation and silent aspiration associated with cuff deflation, as well as to avoid mucosal damage due to excessive pressure in the cuff.
\end{abstract}

Tracheal tUBE CUFF VOLUME and pressure changes during nitrous oxide anaesthesia have been reported previously. ${ }^{1-5}$ To our knowledge they have not been studied during extracorporeal circulation when there is minimal pulmonary gas exchange and when the lungs are usually inflated with 100 per cent oxygen. We have noted air leakage past a previously air-tight tracheal cuff seal upon resumption of ventilation during or following extracorporeal circulation, necessitating introduction of additional air into the cuff to re-establish the seal. The increase in cuff volume and pressure during nitrous oxide anaesthesia before bypass may be reversed during extracorporeal bypass. One concern is that there might then be silent aspiration. Decreases in cuff pressure to as low as zero have been observed by the authors during cardiopulmonary bypass.

This study was done to examine the effect of varying the composition of the inspired and intracuff gases on tracheal tube cuff volume during extracorporeal circulation.

\section{MethoD}

The measurements were obtained during coronary artery bypass grafting on 90 patients (15

Shigemasa Ikeda, M.D., Assistant Professor; John F. Schweiss, M.D., Professor and Chairman; Department of Anesthesiology, Saint Louis University School of Medicine, Saint Louis, Missouri, 63104, U.S.A.

Address reprint requests to: Dr. Shigemasa Ikeda, Dept. of Anesthesiology, St. Louis University, 1325 South Grand, St. Louis, Missouri, 63104, U.S.A.

Presented at the Association of Cardiac Anesthesiologists in Hollywood, Florida, March 1979. female and 75 male) when extracorporeal circulation lasted at least 90 minutes. In all men tracheal intubation was with a $9 \mathrm{~mm}$ I.D. and in all females with an $8 \mathrm{~mm}$ I.D. American Hi-Lo (high volume-low pressure) tracheal tube with polyvinyl chloride cuff designed and manufactured by National Catheter Corporation.

Anaesthesia was induced with sodium thiopentone $3-5 \mathrm{mg} \cdot \mathrm{kg}^{-1}$ and maintained with a mixture of nitrous oxide (2 litres/min) and oxygen (1 litre/min), supplemented by morphine sulphate $1-1.5 \mathrm{mg} \cdot \mathrm{kg}^{-1}$. Muscle relaxation was obtained with intermittent doses of pancuronium bromide. Nitrous oxide was the only inhalation anaesthetic administered during the study. Oxygen 100 per cent was introduced into the bubble oxygenator during extracorporeal circulation.

The study was divided into two phases. In the initial phase, in which 30 patients were studied, the cuff was inflated with room air following intubation and the initial cuff pressure was adjusted to $0.98 \mathrm{kPa}\left(10 \mathrm{~cm} \mathrm{H}_{2} \mathrm{O}\right)$ with a Portex Softseal tracheal cuff pressure indicator. The initial cuff pressure of $0.98 \mathrm{kPa}\left(10 \mathrm{~cm} \mathrm{H}_{2} \mathrm{O}\right)$ was $0.29-0.39 \mathrm{kPa}\left(3-4 \mathrm{~cm} \mathrm{H}_{2} \mathrm{O}\right)$ higher than the minimum pressure required to prevent leakage past the cuff with lung inflation pressures of $2.45 \mathrm{kPa}\left(25 \mathrm{~cm} \mathrm{H} \mathrm{H}_{2} \mathrm{O}\right)$.

At the beginning of bypass cuff pressure was readjusted by withdrawing cuff content until a residual pressure of $0.98 \mathrm{kPa}\left(10 \mathrm{~cm} \mathrm{H}_{2} \mathrm{O}\right)$ was re-established. An empty $12 \mathrm{ml}$ Argyle Monoject double seal plastic syringe was attached to the pilot balloon and was not removed thereafter. During extracorporeal circulation the lungs of the 453

Canad. Anaesth. Soc. J., vol. 27, no. 5, September 1980 


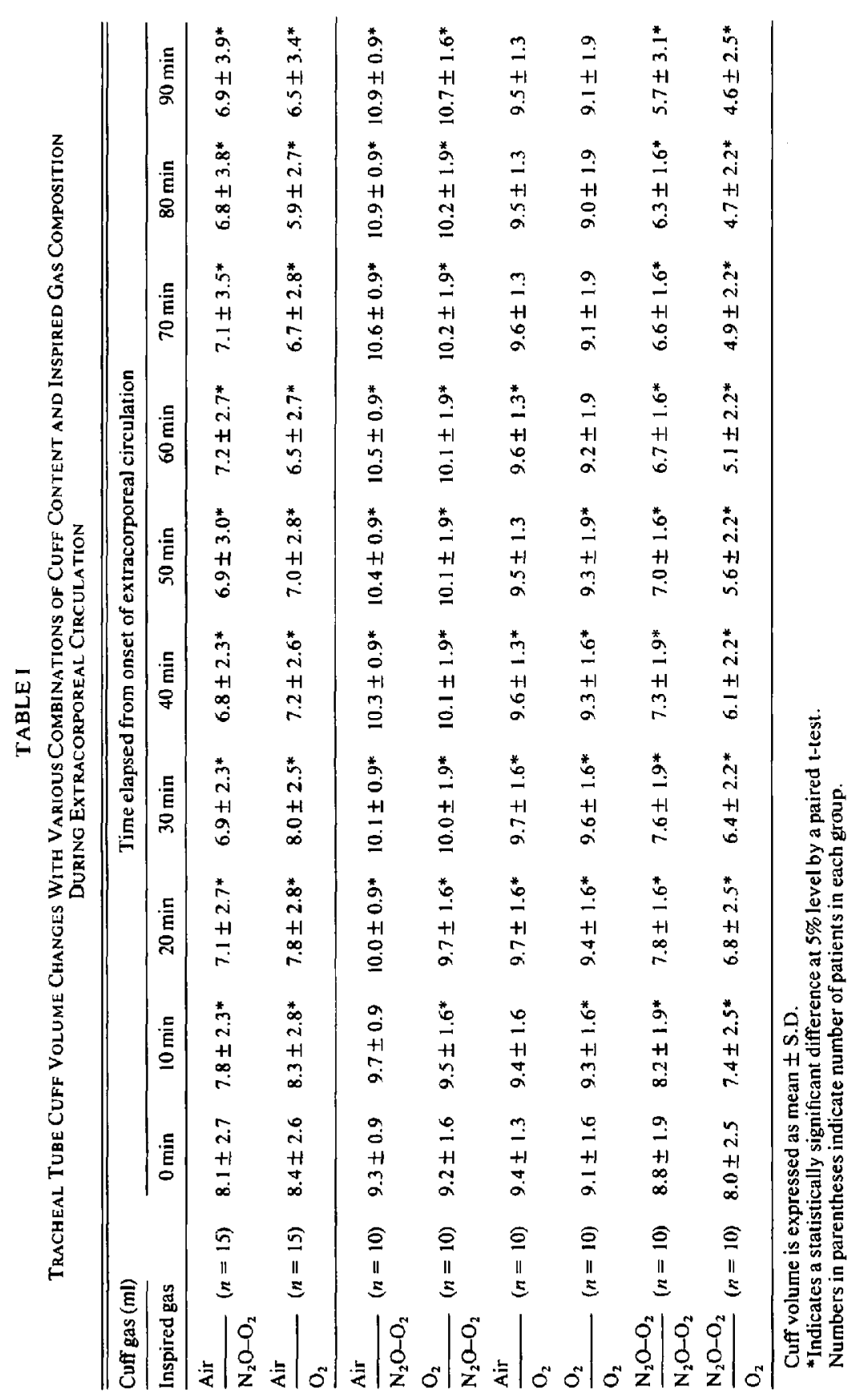


30 patients in this group were inflated with either 100 per cent oxygen ( 3 litres $/ \mathrm{min}$ ) ( 15 patients) or a mixture of nitrous oxide ( 2 litres/min) and oxygen (1 litre/min) until the heart was electively arrested, at which time ventilation was discontinued. Inflow gases into the anaesthesia circuit were unchanged during the period when ventilation was discontinued. Positive end-expiratory pressure was not employed during these studies. Cuff volume changes were measured every ten minutes for ninety minutes using the Argyle Monoject syringe.

Cuff volume was determined by withdrawing air until the pilot balloon collapsed and the reinjection of $0.2 \mathrm{ml}$ produced visible re-expansion of the pilot balloon. This end point is readily reproducible. Actual cuff volumes were measured in millilitres. Before each cuff volume determination oropharyngeal suction was done to minimize the possibility of aspiration during cuff deflation.

In the second phase of the study, 60 patients were divided into three groups of 20 each. In each of the three groups of 20 , the tracheal cuff was deflated at the onset of extracorporeal circulation and then reinflated to $0.98 \mathrm{kPa}\left(10 \mathrm{~cm} \mathrm{H} \mathrm{H}_{2} \mathrm{O}\right)$ pressure with either air, oxygen, or a two-to-one-part mixture of nitrous oxide and oxygen.

Each group of 20 was further subdivided into two groups of ten each by inflating the patients' lungs with either 100 per cent oxygen or a mixture of nitrous oxide ( 2 litres/min) and oxygen (1 litre/min) during extracorporeal circulation following cuff pressure adjustment to $0.98 \mathrm{kPa}$ $\left(10 \mathrm{~cm} \mathrm{H}_{2} \mathrm{O}\right)$. The cuff volume was measured in the same manner as in the initial study. Comparisons within each study group were made by the paired " $t$ " test. Differences were considered significant when $\mathrm{P}<0.05$ compared with the volume at zero time.

\section{RESUlTS}

Mean values of cuff volume and standard error are shown in Table I.

In the initial phase of 30 patients in which the cuff was filled with air immediately after intubation and pressure readjusted to $0.98 \mathrm{kPa}(10 \mathrm{~cm}$ $\mathrm{H}_{2} \mathrm{O}$ ) by withdrawing the cuff gas just before bypass and in which the lungs were inflated with 100 per cent oxygen before ventricular fibrillation or standstill, the cuff volume decreased throughout the bypass period. In those patients in which the cuff was filled with air and in which the lungs were inflated with a mixture of nitrous oxide ( 2 litres/min) and oxygen (1 litre/min) the cuff vol-

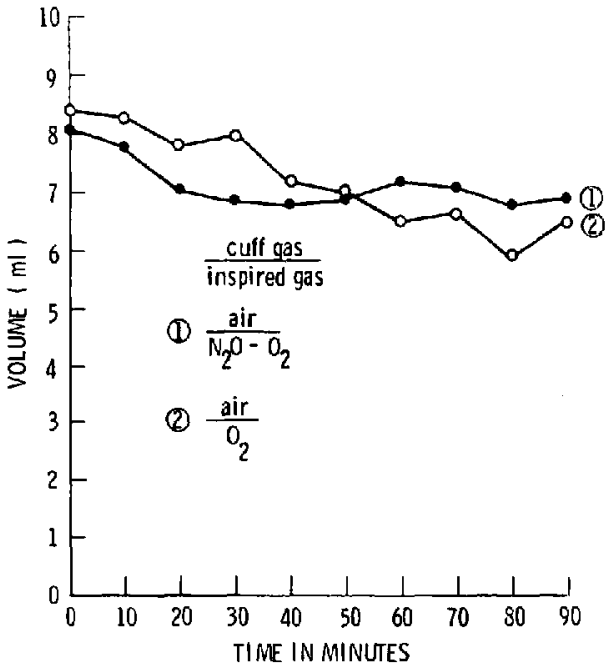

Figure 1 Cuff volume changes during extracorporeal circulation in the initial phase are plotted against time. Tracheal tube culf was filled with air after intubation and the cuff pressure was adjusted to $0.98 \mathrm{kPa}$ $\left(10 \mathrm{~cm} \mathrm{H} \mathrm{H}_{2} \mathrm{O}\right.$ ). The pressure was readjusted to $0.98 \mathrm{kPa}$ $\left(10 \mathrm{~cm} \mathrm{H}_{2} \mathrm{O}\right.$ ) by the withdrawal of cuff content at the beginning of bypass.

ume decreased for the first 30 minutes. Thereafter changes were minimal (Table I and Figure 1).

In the second phase ( 60 patients) of the study the cuff volume changes were dependent upon the gas composition in the cuff (air, oxygen, or nitrous oxide-oxygen) and the composition of the inspired gas (oxygen or nitrous oxide). When the cuff was filled with the nitrous oxide-oxygen mixture, the cuff volume decreased during bypass regardless of the inspired gas, but a greater decrease was seen when the inspired gas was pure oxygen, as compared to the nitrous oxide-oxygen mixture. When the cuff was filled with either air or oxygen and the lungs were inflated with a gas mixture containing nitrous oxide the volume of the cuff increased with time. When the cuff was filled with either room air or 100 per cent oxygen and the lungs were inflated with oxygen, cuff volume change was negligible (less than $0.4 \mathrm{ml}$ ) (Table I and Figure 2).

\section{Discussion}

In our institution it is customary to inflate the lungs with 100 per cent oxygen during extracorporeal circulation. It was reasonable to anticipate that the difference in composition between the gas in the cuff and the ventilating gas would result 


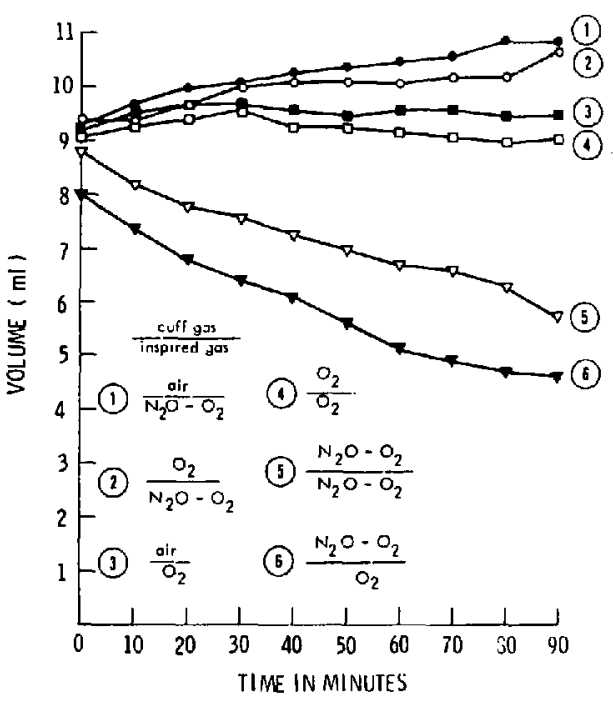

Figure 2 Cuff volume changes during extracorporeal circulation in the second phase of the study are plotted against time. Tracheal tube cuff was inflated with either air, or nitrous oxide and oxygen at the beginning of bypass and the pressure was adjusted to $0.98 \mathrm{kPa}\left(10 \mathrm{~cm} \mathrm{H}_{2} \mathrm{O}\right)$.

in volume and/or pressure changes due to gas transfer.

The cuff volume increase when the cuff was filled with air and the lungs were inflated with a nitrous oxide-oxygen mixture is due to nitrous oxide diffusion into the air-filled cuff. ${ }^{1.2}$ Similarly the increase of cuff volume observed when the cuff was filled with oxygen and the lungs were inflated with a nitrous oxide mixture is also due to the diffusion of nitrous oxide into the oxygenfilled cuff.

Transfer of gas should be very limited if the inspired gas mixture and the cuff content are identical. However, a decrease in cuff volume was observed during cardiopulmonary bypass when nitrous oxide-oxygen was the inspired gas and the cuff contained gases of similar concentration. The likely explanation is that the tracheal mucosa has a negligible tension of nitrous oxide and the cuff filled with nitrous oxide in contact with the mucosa allows nitraus oxide to diffuse from the cuff into the mucosa at a more rapid rate than that at which it diffuses into the cuff area not in contact with the mucosa. Some nitrous oxide might also diffuse through the pilot balloon into the atmosphere, thus further reducing cuff volume. The thickness of the wall of the tracheal tube is $\mathbf{4 0}$ to 50 times that of the cuff. Significant transfer of gas through the wall of the tracheal tube would not occur during the time period of the study, due to its thickness.

We chose a cuff inflation pressure of $0.98 \mathrm{kPa}$ $\left(10 \mathrm{~cm} \mathrm{H}_{2} \mathrm{O}\right)$ based upon our observation of an effective seal against air leakage past the cuff over an airway inflation pressure of $0-3.92 \mathrm{kPa}$ $\left(0-40 \mathrm{~cm} \mathrm{H} \mathrm{H}_{2} \mathrm{O}\right)$. A pressure of $0.98 \mathrm{kPa}(10 \mathrm{~cm}$ $\mathrm{H}_{2} \mathrm{O}$ ) against the mucosa is less than the capillary perfusion pressure ${ }^{6}$ and should minimize the possibility of ischaemic damage due to pressure.

In our initial study, in which the cuff was filled with air immediately following intubation, the gases in the cuff would have contained a considerable amount of nitrous oxide at the beginning of extracorporeal circulation due to nitrous oxide transfer by diffusion. The volume of nitrous oxide transferred into the air-inflated tracheal tube cuff is known to increase with time during exposure of the air-filled cuff to a nitrous oxideoxygen mixture. ${ }^{1,2}$

In both groups of the initial study and in two groups of the second study in which the cuff contained nitrous oxide, the cuff volume decreased regardless of the composition of the inspired gas, but the decrease was greatest with 100 per cent oxygen as the inspired gas. The decrease observed when nitrous oxide was the inspired gas could be accounted for by diffusion of the nitrous oxide through the larger area of cuff surface in contact with the tracheal mucosa, in which nitrous oxide was negligible.

In the first group of the initial phase, in which the cuff was filled with air with pressure adjusted to $0.98 \mathrm{kPa}\left(10 \mathrm{~cm} \mathrm{H}_{2} \mathrm{O}\right)$ at initiation of bypass, and in which the lungs were inflated with the nitrous oxide-oxygen mixture before and during bypass, the cuff volume decreased for the first 30 minutes; thereafter changes were minimal. The probable explanation appears to be that during bypass the loss of nitrous oxide from the cuff to the tissues was offset by input from the gas mixture through the area of the cuff not in contact with tracheal mucosa so that equilibrium was reached after 30 minutes of extracorporeal circulation.

Stanley and Liu, ${ }^{3}$ Revenäs and Lindholm ${ }^{4}$ reported constant cuff volume and pressure during anaesthesia when the lungs were ventilated with a gas mixture containing nitrous oxide and oxygen and the cuff was filled with the gas of the same composition. We observed a decrease in cuff volume during bypass. The likelihood is that during bypass the cuff area is exposed to tracheal mu- 
cosa which does not contain nitrous oxide and thus nitrous oxide diffuses out of the cuff into the mucosa.

Although hypothermia could influence gas pressure/volume relationships it plays little role in the changes of the cuff volume under the conditions of our study, since lowering the body temperature $10^{\circ} \mathrm{C}$ would decrease cuff volume by only 3.2 per cent of the initial volume. ${ }^{7}$

In conclusion, when the cuff is filled with either room air or, preferably, 100 per cent oxygen at the start of the extracorporeal circulation and the lungs are inflated with oxygen, the volume change is negligible during extracorporeal circulation. This combination of gas prevents an undesirable decrease in the cuff pressure, loss of seal, and potential silent aspiration. It is somewhat impractical to deflate and reinflate the cuff at the onset of bypass, because this alone might result in gravitational soiling of the respiratory tract from the pharynx or from the area above the cuff within the trachea or larynx which cannot be effectively suctioned.

It might therefore appear prudent to monitor the pressure within the cuff at all times and to keep the pressure at $0.98 \mathrm{kPa}\left(10 \mathrm{~cm} \mathrm{H} \mathrm{H}_{2} \mathrm{O}\right)$ to maintain an effective seal in patients undergoing cardiopulmonary bypass; or to use a cuffed tracheal tube embodying the principle of the Lanz tube inflated with either air or oxygen to minimize the possibility of mucosal damage or gravitational pulmonary contamination.

\section{REFERENCES}

1. STANLEY, T.H. Effects of anesthetic gases on endotracheal tube cuff gas volumes. Anesth. \& Analg. 53: 480 (1974).

2. Stanley, T.H., Kawamura, R. \& Graces, C. Effects of nitrous oxide on volume and pressure of endotracheal tube cuffs. Anesthesiology 41:256 (1974).

3. Stanley, T.H. \& LiU, W.S. Tracheostomy and endotracheal tube cuff volume and pressure changes during thoracic operations. Ann. Thorac. Surg. 20: 144 (1975).

4. Revinäs, B. \& Lindholm, C.E. Pressure and volume changes in tracheal tube cuffs during anaesthesia. Acta Anaesth. Scand. 20: 321 (1976).

5. Stanley, T.H. Nitrous oxide and pressures and volumes of high and low pressure endotracheal tube cuffs in intubated patients. Anesthesiology 42: $637(1975)$.

6. GuYton, A. C. Textbook of Medical Physiology, 5th ed. Philadelphia, W.B. Saunders, p. 390(1976).

7. McIntosh, R., Mushin, W.W.\& Epstein, H.G. Physics for the Anaesthetist, 2nd ed. Springfield, Charles C. Thomas, p. 114 (1958).

\section{RÉSUMÉ}

Les changements de volume du ballonnet des tubes trachéaux ont été étudiés pendant la circulation extracorporelle pour déterminer les effets de la composition des gaz inspirés et des gaz du ballonnet. Cette étude a porté sur 90 patients qui subissaient un pontage aortocoronarien.

Lorsque le ballonnet contenait du protoxyde d'azote au début de la circulation extracorporelle, le volume du ballonnet a diminué pendant le pontage quelque soit la composition de gaz inspiré. Lorsque le ballonnet est vérifié d'air ou d'oxygène, le volume du ballonnet est dégonfé et ensuite empli soit avec de l'air ou de l'oxygène au début de la circulation extracorporelle et que les poumons sont ventilés à l'oxygène, le changement de volume du ballonnet est minime pendant le pontage. Ce mélange de gaz prévient tout changement indésirable du volume du ballonnet. Il semble désirable de monitoriser le volume ou la pression du ballonnet du tube trachéal et de maintenir un volume ou une pression constante pendant le pontage pour éviter la déplation et l'aspiration silencieuse associée à la déftation du ballonnet, aussi bien pour éviter d'endommager la muqueuse trachéale par pression excessive par le ballonnet. 